\title{
Japanese consumer preferences for additive-free wine labeling
}

\author{
Satoko Kubota ${ }^{1 *}$ (D), Hirotsugu Sawano ${ }^{2}$ and Hiroichi Kono ${ }^{1}$
}

\author{
* Correspondence: \\ skubota@obihiro.ac.jp \\ ${ }^{1}$ Department of Animal and Food \\ Hygiene, Obihiro University of \\ Agriculture and Veterinary Medicine, \\ Nishi 2-11, Inada-cho, Obihiro, \\ Hokkaido 080-8555, Japan \\ Full list of author information is \\ available at the end of the article
}

\begin{abstract}
Consumers have recently become more concerned about food additives and food safety. Since its first meeting on September 17, 2003, the Risk Communication Expert Committee has studied and discussed the ideal methods to communicate risk related to food safety issues in response to a Food Safety Commission request. However, there are only a few case studies that actually apply to risk communications. This study aims to analyze consumer preferences for antioxidantfree wine and suggest a tool for risk communications. The study uses a two-stage method: in the first, the analysis identified different types of consumers according to their views of antioxidant-free labels using structural equation model (SEM) analysis; the second stage incorporated the consumer attributes identified by the SEM into a conjoint analysis to calculate willingness to pay (WTP) for each attribute. The WTP results show that the antioxidant-free label has a significant influence on consumer preferences. Notably, consumers who recognize food additive dangers placed significant additional value on wine without antioxidants. On the other hand, consumers who have knowledge of wine and food processing tended to view antioxidant-free wine as low in quality compared to wines made with the original manufacturing process. These results indicate that "adverse selection" has occurred in the wine market in Japan. The results suggest significant differences between consumer groups in terms of awareness of the dangers of food additives and knowledge of wine and food processing. This implies that some consumers are sensitive to food additives. Our research can help regulators create effective means to communication risk related to food additives. In addition, this implies that government guidelines related to wine labels are important, so that Japanese wine may approach international level quality.
\end{abstract}

Keywords: Antioxidant-free wine, Conjoint analysis, Food safety, Risk communication, Structural equation models

\section{Background}

In recent years, it has become increasingly common to see publications, news reports, and advertisements, specifically emphasizing the "dangers" of food additives. Many of these ignore dose-response relationships and give the mistaken impression that additives have the same toxicity at low concentrations below maximum allowable standards as they do if ingested in high quantities. Turning the disparity between "safety" and "perception of safety" at the consumer level to their advantage, manufacturers have implemented "reassurance measures" to respond to consumer needs. Most

(c) The Author(s). 2017 Open Access This article is distributed under the terms of the Creative Commons Attribution 4.0 International License (http://creativecommons.org/licenses/by/4.0/), which permits unrestricted use, distribution, and reproduction in any medium, provided you give appropriate credit to the original author(s) and the source, provide a link to the Creative Commons license, and indicate if changes were made. 
of these measures constitute efforts to reduce the already low risks even further-in other words, efforts to achieve zero risk.

Among the recent researches related to such manufacturers' reassurance measures, Ikumoto et al. (2011) empirically analyzed the relationship between consumer misperception and information disclosure on product labels. Focusing on vegetable cooking oil labels, they investigated consumer responses to manufacturer-provided information. The findings indicate that consumers respond excessively to "no cholesterol" labels, which have no practical meaning for vegetable oil. These and other similar results indicate that consumers do not adequately understand the information that manufacturers provide that is intended to reassure consumers of the safety of their products. This suggests that government efforts to establish guidelines for food product labels are a useful strategy to deal with the overwhelming flood of information that consumers face.

From this, it is clear that manufacturers use "zero" and "additive-free" labels strategically as a means to reassure consumers. However, such labeling may, in reality, reduce the value of the commodity itself and may hinder healthy business promotion. In this study, we examine the case of "antioxidant-free wine," in which "additive-free" labeling appears to be lowering the value of the commodity itself, and analyze how consumers perceive the information provided by manufacturers and clarify the purpose of regulating manufacturers' product labels. We focus on wine because adding the antioxidant to wine during the production and maturing process is actually important. Therefore, we expect that consumers who are aware of the process will have a negative view of antioxidant-free wine.

In the case of new food technology, consumers tend to accept negative information more than positive information, even if there are many merits to the technology. Aoki et al. (2010) clarified the factors affecting individual purchase decisions in a laboratory experiment and contingent environment using ham sandwiches with and without a sodium nitrite as the target. Consumers tended to avoid sodium nitrite, whether or not they were provided with detailed information including its positive and negative role. In the laboratory experiment, the main factor affecting the purchasing decision was the flavor information. The information associated with health risk had the most effect in the case of the contingent environment. On the other hand, Markosyan et al. (2009) analyzed US consumers' willingness to pay (WTP) for apples enriched with an antioxidant coating and showed that consumers were willing to pay the small premium for apples enriched with antioxidants. However, consumers who prefer organic retailers were less likely to pay a premium for apples enriched with antioxidants. Hayes et al. (2002) focused on pork treated with radiation to control the parasite Trichinella. Consumers provided with both the positive and negative information at the same time tended to control the negative information. Additionally, consumers received this unscientific negative information from a consumer advocacy group. In Japan and Europe, consumers tend to avoid genetically modified (GM) food products because they believe that GM food products have harmful effects on health. McCluskey et al. (2003) clarified the factors affecting Japanese consumer's willingness to accept (WTA) GM food products. Japanese consumers requested a $60 \%$ discount for GM noodles compared with non-GM noodles. The increased WTA was influenced by food safety and the environment, self-reported knowledge about biotechnology, self-reported risk perceptions of GM foods, income, and education. Therefore, companies that want to sell GM products should engage with biotechnology education and communicate risk to Japanese consumer. Lusk et al. (2003) analyzed the WTP for beef steaks from cattle without growth 
hormones or GM corn in France, Germany, UK, and USA. The study found that French, German, and UK consumers had higher WTP than US consumers for both cases for cattle not administrated with growth hormones and not fed with GM corn. Li et al. (2004) found similar results. Although most US consumers requested a GM label for GM corn-fed beef, the mean discount for beef with a GM label was 8\%, which is less than in Europe and Japan. The authors concluded that consumers who are unaware of some basic information about GM food should be provided with this information to improve their positive intentions.

In this context, although manufacturers supply significant scientific information for food safety, consumers do not understand it enough. Therefore, "zero" and "additivefree" labels are one means through which consumers gain a feeling of security around food safety. However, this behavior from manufacturers could destroy food culture. Therefore, it is necessary to address consumers' concerns, that is, it is important for manufacturers and governments to risk communicating with consumers. The present study investigates the Japanese wine industry to analyze consumer preferences for antioxidant-free labels and to suggest a tool for risk communication.

\section{Wine labeling system in Japan}

Japanese law treats wine as a fruit liquor. The main labeling laws are the "Act on Securing Liquor Tax and on Liquor Business Associations," "Food Sanitation Act," and "Act against Unjustifiable Premiums and Misleading Representations." The first law regulates the labeling for the producer's name and address, capacity, item of liquor, ratio of alcohol, and so on. Moreover, notification of the National Tax Agency depends on the law that sets the standard rule for labeling geographical indications. The second law regulates labeling for food additives, allergen contents, genetically modified contents, and so on. Notification no. 370 of the Ministry of Health, Labor and Welfare based on the Food Sanitation Law also contains a standard for food additives. In this notification, sodium sulfite and sodium hyposulfite (antioxidant additives) for fruit liquor must be below $0.35 \mathrm{~g} / \mathrm{kg}$ (residues as $\mathrm{SO}_{2}$ ). The third law prohibits any representation to general consumers that the food item is much better than that of the actual goods or services, or are portrayed as being, contrary to the fact, much better than those of the other entrepreneurs who supply the same kind or similar goods or services as those supplied by the producer. On the other hand, many foreign countries have their own laws related to wine that outline rules for labeling the production area, grade, ripening conditions, alcohol content, and so on. Although there is no rule for wine only, the "Standards of Representation of Domestic Wines" was established as a voluntary standard by the council for studying the issue of wine appellations is the substance of Japan's wine-related law. Article 7, Paragraph 1 of this standard contains a rule related to additive-free labeling, "Do not display as 'additivefree, if you do not write a factor following 'additive-free' on a wine made from grape only-(like 'antioxidant additive-free')." Moreover, the font size for "additive-free" must not be larger than the size of factor display. In other words, the present standards in Japan do not prohibit additive-free labeling and allow for highlighting whole words.

Wine is a natural, agricultural product recognized by European Union (EU) treaties and defined in Comité Européen des Entreprises Vins (CEEV)EU legislation as a "product obtained exclusively from the total or partial alcoholic fermentation of fresh grapes, whether or not crushed, or of grape mus." (Comité Européen des Entreprises Vins 
(CEEV) 2016b). In EU member countries, ingredients and nutritional labeling in wine and beverages are exempted according to a new regulation (EU regulation 1169/2011) and allow for authorized food additives, including an explicit reference to the specific EU Common Market Organization (CMO) rules on Oenological Practices for wines (Comité Européen des Entreprises Vins (CEEV) 2016a). However, under EU law, the threshold level for sulfur dioxide in wine is $10 \mathrm{mg} / \mathrm{l}$ (Finch 2016).

\section{Methods}

\section{Overview of the questionnaire survey}

In preparation for the actual investigation, we conducted a pre-survey with 35 individuals associated with the Obihiro University of Agriculture and Veterinary Medicine. Because many of the subjects included in the pre-survey did not drink wine, we targeted individuals who either purchase or drink wine in the actual survey. The main survey also includes demographic attributes, including sex, marital status, occupation, age, and income, in addition to the questions for the structural equation model (SEM) and conjoint analysis used for data analysis.

In the main survey, we selected a specialty store that sells premium brand wine, a general liquor store that sells inexpensive wine, and a wine-related facility in Hokkaido prefecture. According to statistics from Japan's National Tax Agency (2015), Hokkaido has Japan's largest production area for wine grapes (3305 t, 16.4\%, in FY 2014). We then chose Sapporo City, which is the main consumption area; Obihiro City, which is a farming area; and Ikeda Town with Hokkaido's oldest winery. We conducted the survey from October to December 2010 by distributing questionnaires to customers at wine shops, general liquor stores, and wineries and collected the responses via mail. We distributed the survey to 700 people and collected 186 respondents, a response rate of $26.6 \%$.

\section{Structural equation model}

We use a structural equation model (SEM) to clarify the relationships between one or more independent variables and one or more dependent variables. In Fig. 1, we illustrate the relationships among the variables in a path diagram and calculate the path coefficients (Hox and Bechger 1998; Kaplan 2008).

In the SEM, the latent variables inferred by the observed variables are often introduced. We referenced questions and latent variables from Aizaki et al. (2004) and Cacioppo et al. (1984). For latent variables, we used questions related to frequency of wine drinking (Q1), knowledge of wine-related terms (Q6-1 3), knowledge of and attitude toward food safety (Q13-1 12), knowledge of and attitude toward wine (Q13-13 17), action in daily life (Q14-1 5), food purchasing behavior (Q14-6 16), knowledge of food and wine processing (Q15-1 11), and acknowledgment level for risk factors (Q16). Respondents answered the questions on a 5-point scale (1: I don't know at all/I don't think so at all to 5: I know well/I think so a lot), except for Q1 and Q16. Q1 used a scale ranging from 1, "several times a year;" 2, "several times a month;" 3, "once a week;" 4, "several times a week;" and 5, "almost every day." For Q16, respondents had five options: "unbalanced nutrition," "naturally occurring toxins," "toxins from microorganisms," "food additives or residual agricultural chemicals," and "environmental contaminants such as acid rain and dioxins," 


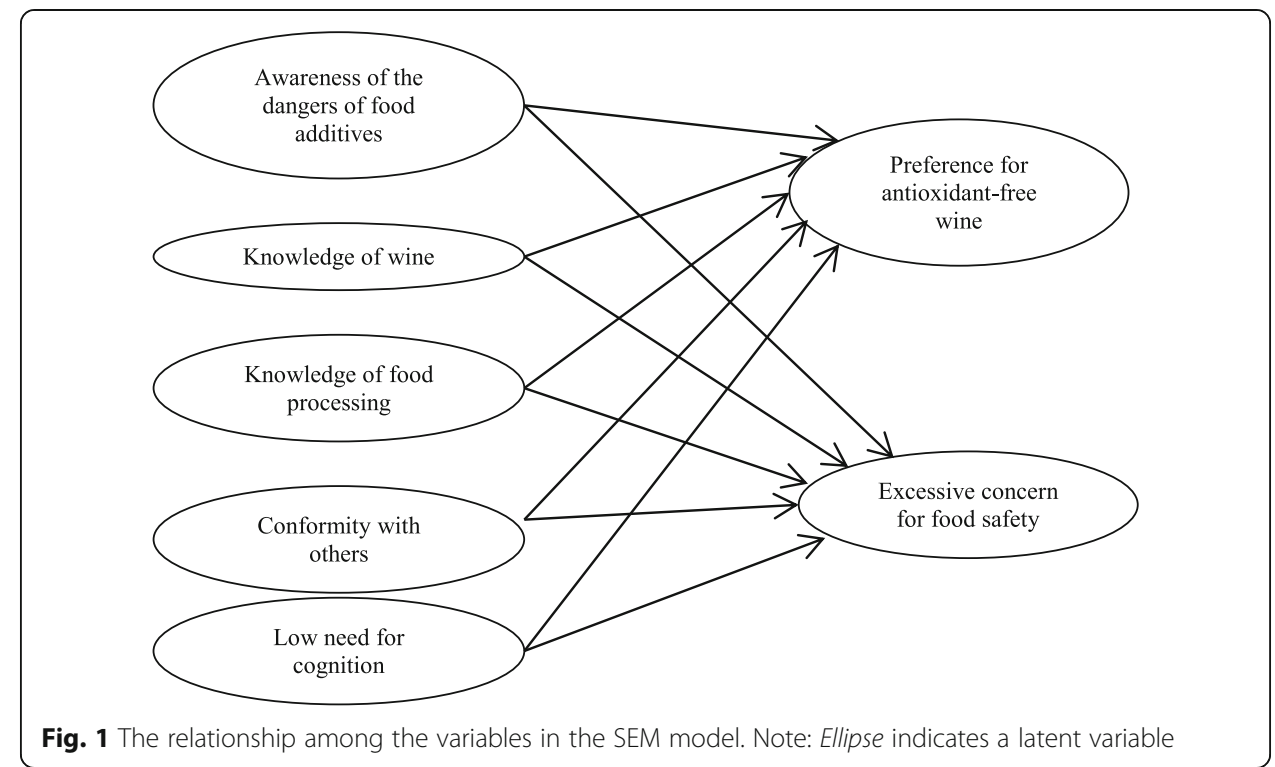

and request a list for five factors. We then check the risk for "food additives or residual agricultural chemicals."

An extremely biased variable is unsuitable among the candidate index variables. Therefore, we exclude variables that have a ceiling effect (average value + standard deviation above 5) and floor effect (average value - standard deviation below 1). We use searching factorial analysis to examine the latent variables and obtained seven latent variables (see Table 4). In our model, we assume that knowledge and attitude affect preferences and/or excessive concern. Therefore, we established five latent variables, "awareness of the dangers of food additives," "knowledge of wine," "knowledge of food processing," "conformity with others," and "low need for cognition," as the independent variables. We also established two latent variables, "preference for antioxidant-free wine" and "excessive concern for food safety," as the dependent variables. Consumers with restricted information and/or time tend not to process unimportant information. In other words, these consumers make decisions using only unique information (Dhar and Nowlis 1999). Therefore, consumers with a high tendency of "conformity with others" and "low need for cognition" could possibly purchase antioxidant-free wine as an added value good. Moreover, consumers with specific knowledge tend to have a keen interest in the specifics. A high tendency toward "awareness of the dangers of food additives" might have a positive effect on "preference for antioxidant-free wine" and "excessive concern for food safety." On the other hand, "knowledge of wine" might produce the opposite results. In the case of "knowledge of food processing," we confirm the consumer's knowledge based on scientific information as well as its influence on "preference for antioxidant-free wine" and "excessive concern for food safety."

\section{Choice-based conjoint analysis}

Table 1 summarizes the wine attributes and standards, which were established by the Wine Survey conducted by Japan's National Tax Agency (2008) and pre-survey of the staff of Obihiro University of Agriculture and Veterinary Medicine. In Japan's National 
Table 1 Sample attributes and standards

\begin{tabular}{llll}
\hline Attribute & Standards & \\
\hline Price (JPY/750 ml) & (1) 750 & (2) 1000 & (3) 1250 \\
Source & (4) 1500 & (5) 2000 & (6) 3500 \\
"Antioxidant additive-free" label & (1) France & (2) Chile & (3) Japan \\
"Organic" label & (1) Present & (2) Absent & \\
\hline
\end{tabular}

Tax Agency's (171 samples) survey, the respondents' important factors in buying wine were "taste and flavor (28.7\%)," "varieties of grape (16.1\%)," "price (14.4\%)," and "source (9.6\%)." It is difficult to ask about the difference between taste and flavor, and there are many varieties of grapes, so we cannot focus on only a few. We thus used price and source as attributes for the conjoint analysis based on the pre-survey and that by Japan's National Tax Agency (2008). The attributes also include "antioxidant additive-free" label and "organic" label; the first to determine consumer preferences for additive-free and the second to determine consumer preferences for high levels of food safety. Based on the number of attributes and standards, there are theoretically 72 possible wine profiles; however, we adopt an orthogonal planning method to reduce the number of profiles to 24. As we show in Fig. 2, one question set included two profiles and "no-buy." We divide the respondents to four groups and ask six question sets that are selected randomly.

We performed an overall analysis of the data utilizing a conditional logit model by specifying a random utility model in which the utility function $U_{k i}$, when respondent $k$ chooses option $i$, is expressed by

$$
U_{k i}=V_{k i}+\varepsilon_{k i}
$$

where $V_{k i}$ specifies an observable discrete element among the utilities and $\varepsilon_{k i}$ specifies a non-observable stochastic element. When there are three choices, given that the choice probability $P_{k i}$ (the respondent will choose $i$ from among the choice set $C=\{1,2,3\}$ for scenario $j)$ is higher if the utility $\left(U_{k i}\right)$ of selecting $i$ is higher than the utility $\left(U_{k j}\right)$ of making an alternate selection $(j(j \neq i))$, we use the following expression:

$$
\begin{aligned}
P_{k i} & =\operatorname{Pr}\left(U_{k i}>U_{k j}, \forall j \in C, j \neq i\right) \\
& =\operatorname{Pr}\left(V_{k i}-V_{k j}>\varepsilon_{k j}-\varepsilon_{k i}, \forall j \in C, j \neq i\right)
\end{aligned}
$$

In the conditional logit model, we assume that the probabilities of stochastic elements $\varepsilon_{k i}$ and $\varepsilon_{k j}$ fit a Gumbel distribution. In that case, we can express the choice probability that individual $i$ will choose scenario $j$ as follows:

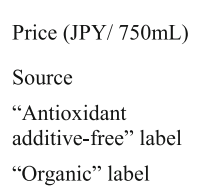

\begin{tabular}{|c|c|c|}
\hline$\square$ & $\square$ & $\square$ \\
\hline 2,000 & 1,500 & \\
\hline France & Chile & No-buy \\
\hline Present & Absent & \\
\hline Present & Present & \\
\hline
\end{tabular}

Fig. 2 Example question set. Note: Each respondent is asked to select one of three alternatives 


$$
P_{k i}=\frac{\exp \left(\lambda V_{k i}\right)}{\sum_{j=1}^{3} \exp \left(\lambda V_{k j}\right)}
$$

where $\lambda$ is the scaling parameter that is typically standardized to a value of 1 .

Furthermore, if $d_{k i}$ is a dummy that takes a value of 1 when respondent $k$ selects the choice $i$, and a value of 0 when the respondent chooses something other than $i$, we can express the log likelihood $\ln L$ as below, and we can estimate the function parameter for the fixed utility using the maximum likelihood method.

$$
\ln L=\sum_{\mathrm{k}} \sum_{i=1}^{3} d_{k i} \ln P_{k i}
$$

We use the following indirect utility function:

$$
V_{k i}=\sum_{\mathrm{m}} \beta_{i m} X_{i m}+\sum_{\mathrm{m}} \sum_{\mathrm{n}} \gamma_{i m n} X_{i m} S_{n k}
$$

where $\beta_{i m}$ and $\gamma_{i m n}$ are estimated parameters, $X_{i m}$ is the $m$ th attribute of wine option $i$, and $S_{n k}$ is the $n$th attribute of the $k$ th respondent. The primary objective of this analysis is to incorporate the latent variables related to consumers' perception (awareness) obtained from the covariance structural analysis into utility models as consumers' attributes, and to thereby quantitatively determine consumers' appraisals of wine labels. To this end, we first transformed each latent variable into dummy variables to indicate the presence (1) of or absence (0) of knowledge (awareness). We combined these with dummy variables for the labels "antioxidant additive-free" (present $=1$; absent $=0$ ), "organic" (present $=1$; absent $=0$ ), "product of France" (product of France $=1$, product of Chile $=0$, product of Japan $=0$ ), "product of Chile" (product of France $=0$, product of Chile $=1$, product of Japan $=0$ ), and "product of Japan" (product of France $=0$, product of Chile $=0$, product of Japan $=1$ ), which we include in the wine attribute variable $X_{i m}$ and specified in the utility model as explanatory variables.

Furthermore, by dividing the attribute evaluation weights, which are the parameters of the attributes under analysis, we can evaluate the weight of the cost burden and thus transform the unitless attribute evaluation into units of currency.

\section{Results and discussion}

\section{Characteristics of respondents}

Table 2 shows the respondent's composition ratio by sex and age. In Japan, the Act for Prohibiting Minors from Drinking restrains young people under 20 years old from drinking alcohol. Therefore, our research target was the people from 20 years old. Comparing to the statistics of research area, the respondent's ratio of middle age group was higher, while the respondent's ratio of 70 years old or more was lower. One of the reasons is that young and senior people tend to drink less amount of wine as compared to others. This is consistent with the results of Japan's National Tax Agency (2008). Additionally, the data collection method by distributing the questionnaire in front of a store or via a mail might have been a burden for 70-year-olds or more.

The income level of the respondent is higher than that of the statistics data (Table 3). This is because the income elasticity of wine demand in Japan is more than 1 (Arahata 2004). In other words, wine is a luxury goods, which means a person with higher income is more likely to purchase wine. 
Table 2 Respondent's comparison ratio by sex and age compared with statistical data

\begin{tabular}{|c|c|c|c|c|c|c|}
\hline \multirow[t]{3}{*}{ Age (years old) } & \multicolumn{4}{|c|}{ Respondents } & \multicolumn{2}{|c|}{ Statistics of research area } \\
\hline & \multicolumn{2}{|l|}{ Male } & \multicolumn{2}{|l|}{ Female } & \multirow{2}{*}{$\begin{array}{l}\text { Male } \\
\text { Ratio (\%) }\end{array}$} & \multirow{2}{*}{$\begin{array}{l}\text { Female } \\
\text { Ratio (\%) }\end{array}$} \\
\hline & Number & Ratio (\%) & Number & Ratio (\%) & & \\
\hline $20-29$ & 11 & 9.322 & 10 & 14.706 & 15.224 & 13.918 \\
\hline $30-39$ & 26 & 22.034 & 16 & 23.529 & 18.816 & 17.236 \\
\hline $40-49$ & 16 & 13.559 & 18 & 26.471 & 17.050 & 16.280 \\
\hline $50-59$ & 37 & 31.356 & 16 & 23.529 & 16.725 & 16.091 \\
\hline $60-69$ & 25 & 21.186 & 8 & 11.765 & 16.821 & 16.742 \\
\hline 70 or more & 3 & 2.542 & 0 & 0.000 & 15.365 & 19.733 \\
\hline Sum & 118 & 100.000 & 68 & 100.000 & 100.000 & 100.000 \\
\hline
\end{tabular}

Source: Statistics Bureau, Ministry of Internal Affairs and Communications (2011). Note: The ratios shown in the statistics of research area are the sum rates of Sapporo City, Obihiro City, and Ikeda Town

\section{SEM results}

Table 4 reports the means of the observed variables, which we use in the SEM. After excluding the items with ceiling and floor effects, the means of the remaining items do not deviate from the average of 3 . Based on our analysis, we completed a final causal structural model comprising the paths and factors of "awareness of the dangers of food additives," "knowledge of wine," "knowledge of food processing," "conformity with others," and "low need for cognition" as exogenous variables that explain the "preference for antioxidant additive-free wine" and "excessive concern for food safety." Table 5 presents the results of the SEM analysis.

The paths from the exogenous latent variable "awareness of the dangers of food additives" to both endogenous variables were significant and positive. Consumers who were aware of the risk of food additives evaluated antioxidant additive-free wine positively. These consumers also showed a fairly extreme attitude of "excessive concern for food safety."

The path from the latent variable "knowledge of wine" to "preference for antioxidant additive-free wine" was significant and negative. In other words, consumers who were knowledgeable about wine had a negative perception of antioxidant additive-free wine.

Table 3 Respondents' income ratio compared with statistics data

\begin{tabular}{llrc}
\hline Income (JPY) & \multicolumn{2}{l}{ Respondents } & \multicolumn{2}{c}{$\begin{array}{c}\text { Statistics of research area } \\
\text { Rate (\%) }\end{array}$} \\
\cline { 2 - 3 } Lumber & Rate (\%) & 27.943 \\
2-2.9 million & 10 & 5.376 & 17.944 \\
3-3.9 million & 14 & 7.527 & 15.223 \\
4-4.9 million & 24 & 12.903 & 10.192 \\
5-5.9 million & 28 & 15.054 & 8.612 \\
6-6.9 million & 23 & 12.366 & 6.155 \\
7-7.9 million & 20 & 10.753 & 3.955 \\
8-8.9 million & 18 & 9.677 & 3.516 \\
9-9.9 million & 12 & 6.452 & 1.767 \\
10 million or more & 8 & 4.301 & 4.692 \\
Sum & 29 & 15.591 & 100.000 \\
\hline Source Statistics Bun & 186 & 100.000 & \\
\hline
\end{tabular}

Source: Statistics Bureau, Ministry of Internal Affairs and Communications (2013). Note: Data for each municipality were not available. Therefore, the data of statistics of research area shows that of the economic area (Sapporo City: Dooh area, Obihiri City, and Ikeda Town: Doto area) 
Table 4 List of observable variables

\begin{tabular}{|c|c|c|c|}
\hline Latent variable & Variable & Contents & Mean score \\
\hline \multirow[t]{3}{*}{$\begin{array}{l}\text { Awareness of the dangers } \\
\text { of food additives }\end{array}$} & Q13-4 & $\begin{array}{l}\text { Agricultural chemicals and food additives are more } \\
\text { dangerous than contamination by microorganisms } \\
\text { or naturally occurring toxins. }\end{array}$ & 3.575 \\
\hline & Q14-7 & $\begin{array}{l}\text { Chemicals listed on food labels (such as calcium } \\
\text { carbonate and copper sulfate) cause me worry. }\end{array}$ & 3.328 \\
\hline & Q16 & $\begin{array}{l}\text { Rank the following risk factors }(A \sim \text { E) that are believed } \\
\text { to affect human health in order of their risk, starting } \\
\text { with the factor representing the highest risk: } \\
\text { A. Unbalanced nutrition B. Naturally occurring toxins } \\
\text { C. Toxins from microorganisms D. Food additives or } \\
\text { residual agricultural chemicals E. Environmental } \\
\text { contaminants such as acid rain and dioxins } \\
\text { (We indicated the score of "Food additives or residual } \\
\text { agricultural chemicals," which adjusted the scores so } \\
\text { that the factor with the highest risk receives a score } \\
\text { of " } 5 \text { " and that with the lowest risk receives a score of "1." }\end{array}$ & 3.726 \\
\hline \multirow[t]{3}{*}{ Knowledge of wine } & Q1 & $\begin{array}{l}\text { Circle the answer that best describes the frequency } \\
\text { with which you drink wine: (5) Almost every day, } \\
\text { (4) Several times a week, (3) Once a week, } \\
\text { (2) Several times a month, (1) Several times a year. }\end{array}$ & 2.952 \\
\hline & Q6-2 & $\begin{array}{l}\text { I know about the AOC system under which French } \\
\text { wines are regulated. }\end{array}$ & 2.828 \\
\hline & Q15-11 & $\begin{array}{l}\text { Antioxidants need to be added to produce high } \\
\text { quality wine. }\end{array}$ & 2.919 \\
\hline \multirow[t]{3}{*}{$\begin{array}{l}\text { Knowledge of food } \\
\text { processing }\end{array}$} & Q13-8 & $\begin{array}{l}\text { It is safer to avoid beef from Miyazaki prefecture, } \\
\text { where there was an outbreak of foot-and-mouth disease. }\end{array}$ & 2.269 \\
\hline & Q15-3 & $\begin{array}{l}\text { If the product is vacuum sealed, microorganisms } \\
\text { cannot grow. }\end{array}$ & 3.118 \\
\hline & Q15-4 & The fresher the meat, the tastier it is. & 1.898 \\
\hline \multirow[t]{2}{*}{ Conformity with others } & Q14-9 & $\begin{array}{l}\text { When I don't have much information about a product, } \\
\text { I sometimes just buy the most popular product. }\end{array}$ & 3.075 \\
\hline & Q14-11 & $\begin{array}{l}\text { The popularity or scarcity of a product } \\
\text { (such as edible chili oil) increases my desire to } \\
\text { buy the product. }\end{array}$ & 2.452 \\
\hline \multirow[t]{3}{*}{ Low need for cognition } & Q14-1 & $\begin{array}{l}\text { Rather than knowing the reason for a certain } \\
\text { answer, it is better to simply know the answer. }\end{array}$ & 2.425 \\
\hline & Q14-2 & I avoid situations that require deep thinking. & 2.559 \\
\hline & Q14-5 & $\begin{array}{l}\text { When reading the newspaper, I skip over articles } \\
\text { that I'm not so interested in. }\end{array}$ & 3.914 \\
\hline \multirow[t]{3}{*}{$\begin{array}{l}\text { Preference for } \\
\text { antioxidant-free wine }\end{array}$} & Q13-13 & $\begin{array}{l}\text { Because the everyday wine that I drink on a regular } \\
\text { basis is not stored for long periods of time, there } \\
\text { is no need for antioxidant additives. }\end{array}$ & 3.183 \\
\hline & Q13-14 & $\begin{array}{l}\text { Antioxidant additive-free wine is safer than wine } \\
\text { to which antioxidants have been added }\end{array}$ & 3.183 \\
\hline & Q13-15 & $\begin{array}{l}\text { I want manufacturers to continue to develop more } \\
\text { health safety-conscious food products such as } \\
\text { antioxidant additive-free wine. }\end{array}$ & 3.704 \\
\hline \multirow{3}{*}{$\begin{array}{l}\text { Excessive concern for } \\
\text { food safety }\end{array}$} & Q13-5 & Natural products are safer than artificial products. & 3.468 \\
\hline & Q13-7 & Japanese products are of the highest quality in the world. & 3.253 \\
\hline & Q13-12 & $\begin{array}{l}\text { I would like to see the introduction of a traceability } \\
\text { system for beef and various other food products. }\end{array}$ & 3.747 \\
\hline
\end{tabular}

Note: Score each item from " 5 " to " 1 " so that the items you most strongly agree with receive a score of " 5, " and those you least agree with receive a score of "1." The scores for items Q13-8 and Q15-4, which are scientifically incorrect statements, were reversed 5 to 1 and 4 to 2, respectively, to make their order comparable to other items. The above list contains only the indicator variables used in the analysis 
Table 5 SEM results

\begin{tabular}{|c|c|c|c|c|}
\hline \multicolumn{3}{|l|}{ Path coefficient } & \multirow{2}{*}{$\begin{array}{l}\text { Estimated value } \\
0.690\end{array}$} & \multirow{2}{*}{$\frac{p \text { value }}{0.000}$} \\
\hline Preference for antioxidant-free wine & $\leftarrow$ & $\begin{array}{l}\text { Awareness of the dangers of } \\
\text { food additives }\end{array}$ & & \\
\hline Excessive concern for food safety & $\leftarrow$ & $\begin{array}{l}\text { Awareness of the dangers of } \\
\text { food additives }\end{array}$ & 0.883 & 0.000 \\
\hline Preference for antioxidant-free wine & $\leftarrow$ & Knowledge of wine & -0.716 & 0.004 \\
\hline Preference for antioxidant-free wine & $\leftarrow$ & Knowledge of food processing & -0.282 & 0.042 \\
\hline Excessive concern for food safety & $\leftarrow$ & Knowledge of food processing & -0.276 & 0.086 \\
\hline Preference for antioxidant-free wine & $\leftarrow$ & Conformity with others & 0.208 & 0.028 \\
\hline Excessive concern for food safety & $\leftarrow$ & Conformity with others & 0.485 & 0.005 \\
\hline Preference for antioxidant-free wine & $\leftarrow$ & Low need for cognition & -0.212 & 0.025 \\
\hline Q13-4 & $\leftarrow$ & $\begin{array}{l}\text { Awareness of the dangers of } \\
\text { food additives }\end{array}$ & 0.656 & - \\
\hline Q14-7 & $\leftarrow$ & $\begin{array}{l}\text { Awareness of the dangers of } \\
\text { food additives }\end{array}$ & 0.514 & 0.000 \\
\hline Q16 & $\leftarrow$ & $\begin{array}{l}\text { Awareness of the dangers of } \\
\text { food additives }\end{array}$ & 0.541 & 0.000 \\
\hline Q1 & $\leftarrow$ & Knowledge of wine & 0.288 & - \\
\hline Q6-2 & $\leftarrow$ & Knowledge of wine & 0.407 & 0.006 \\
\hline Q15-11 & $\leftarrow$ & Knowledge of wine & 0.634 & 0.002 \\
\hline Q13-8 & $\leftarrow$ & Knowledge of food processing & 0.243 & - \\
\hline Q15-3 & $\leftarrow$ & Knowledge of food processing & 0.577 & 0.020 \\
\hline Q15-4 & $\leftarrow$ & Knowledge of food processing & 0.666 & 0.024 \\
\hline Q14-9 & $\leftarrow$ & Conformity with others & 0.775 & - \\
\hline Q14-11 & $\leftarrow$ & Conformity with others & 0.531 & 0.003 \\
\hline Q14-1 & $\leftarrow$ & Low need for cognition & 0.470 & - \\
\hline Q14-2 & $\leftarrow$ & Low need for cognition & 0.966 & 0.115 \\
\hline Q14-5 & $\leftarrow$ & Low need for cognition & 0.149 & 0.018 \\
\hline Q13-13 & $\leftarrow$ & Preference for antioxidant-free wine & 0.572 & 0.000 \\
\hline Q13-14 & $\leftarrow$ & Preference for antioxidant-free wine & 0.737 & 0.000 \\
\hline Q13-15 & $\leftarrow$ & Preference for antioxidant-free wine & 0.686 & - \\
\hline Q13-5 & $\leftarrow$ & Excessive concern for food safety & 0.574 & - \\
\hline Q13-7 & $\leftarrow$ & Excessive concern for food safety & 0.388 & 0.000 \\
\hline Q13-12 & $\leftarrow$ & Excessive concern for food safety & 0.371 & 0.000 \\
\hline GFI & & & 0.781 & \\
\hline RMSEA & & & 0.072 & \\
\hline
\end{tabular}

Antioxidants have long been known as an antimicrobial agent with antioxidant properties (Ough and Crowell 1987). Respondents aware of this information tend to avoid antioxidant additive-free wine. The paths from the exogenous latent variable "knowledge of food processing" to the two endogenous latent variables were both significant and negative, indicating that consumers with correct knowledge of food processing had a negative attitude toward "preference for antioxidant additive-free wine" and "excessive concern for food safety." Bearth et al. (2014) studied consumers' risk and benefit perceptions of artificial food additives and clarified that consumers with knowledge about food additive regulations and trust in these regulations do not have a "risk" perception and accept artificial food additives. This study does not focus 
on regulations on food additives, but our results are similar: consumers with more knowledge of wine and food processing understand food additives.

The paths from the exogenous latent variable "conformity with others" to the two endogenous latent variables were both significant and positive. Consumers that are easily influenced by those around them had a "preference for antioxidant additive-free wine" and exhibit "excessive concern for food safety." According to Fuji Keizai Tokyo (2015), the sales amounts of "additive-free wine" in 2009 and 2010 were 18,400 kl and 18,800 kl, respectively, with a domestic share of the wine market of around $22.7 \%$. This wine already had a fixed share when the investigation into "additive-free wine" started in 2009. That is to say, consumers with high "conformity with others" seem to have a positive image of additive-free wine. Its share has been increasing in Japan (24,400 kl in 2015). Moreover, Hansen et al. (2003) stated, "many experts (scientists, food producers, and public health advisors) regard public unease about food risks as excessive." Therefore, we propose that consumers with "conformity with others" can easily have "excessive concern for food safety."

Finally, the path from the latent variable "low need for cognition" to "preference for antioxidant additive-free wine" was significant and negative. People with "low need for cognition" expend less cognitive effort on a task than those with "high need for cognition" (Verplanken 1993). Given that consumers who express little interest in a variety of things will likely have a similar indifference to food safety, such consumers may also not have much interest in the information provided by manufacturers, are unwilling to pay extra for this added value, and thus have a negative attitude toward such efforts.

\section{Conjoint analysis results}

We developed a conditional conjoint model incorporating the consumer attributes identified by the covariance structural analysis. We report the results in Table 6 .

In Japan's National Tax Agency (2008) survey, the highest price ratio consumers purchase was JPY1000 2000/ $720 \mathrm{ml}$ (44.0\%), followed by JPY2000 3000/ $720 \mathrm{ml}$ (34.9\%). Although there are no data for the average retail price for "antioxidant additive-free wine," "organic wine," "French wine," and "Chilean wine," our results do not differ from those of Japan's National Tax Agency (2008) survey.

The market size of additive-free wine has been increasing. If we look at the interactions between each wine label and consumer attribute, both $\mathrm{M}^{*} \mathrm{~T}$ and $\mathrm{M}^{*} \mathrm{D}$ were significant and positive, indicating that there is a high likelihood that consumers who are aware of the dangers of food additives and consumers who readily conform to others will select wines with antioxidant-free labels. Meanwhile, the interaction terms $M^{*} \mathrm{~W}$ and $M^{*} S$ were significant and negative, indicating that consumers who are knowledgeable about wine and food processing tend to avoid antioxidant-free wines. The $\mathrm{M} * \mathrm{~N}$ interaction was negative, but not significant. The total WTP for wine with an antioxidant additive-free label is JPY2073/750 ml. Furthermore, the maximum prices that the consumers, who are aware of the dangers of food additives and tend toward conformity, were willing to pay were JPY628 and JPY403 for antioxidant-free labeled wine, respectively. Conversely, the maximum prices that consumers knowledgeable of wine and food processing, and with "low need for cognition," were willing to pay JPY $-653,-619$, and -300 , respectively. However, the interactions between labels and "low need for cognition" were not significant. These results indicate that the antioxidant-free 
Table 6 Conditional logit model results

\begin{tabular}{|c|c|c|c|c|}
\hline Variable & Estimated value & $t$ value & & Price of WTP (JPY) \\
\hline ASC (alternate-specific constants) & 1.700 & 14.534 & $* * *$ & 1641.423 \\
\hline Antioxidant additive-free label dummy (M) & 0.447 & 1.261 & & 431.794 \\
\hline $\begin{array}{l}\text { Antioxidant-free label }(M) \times \text { awareness of dangers } \\
\text { of food additives }(T)=\left(M^{*} T\right)\end{array}$ & 0.651 & 3.202 & $* * *$ & 628.339 \\
\hline $\begin{array}{l}\text { Antioxidant-free label }(M) \times \text { knowledge of wine } \\
(W)=\left(M^{*} W\right)\end{array}$ & -0.676 & -3.227 & $* * *$ & -652.969 \\
\hline $\begin{array}{l}\text { Antioxidant-free label }(M) \times \text { knowledge of food } \\
\text { processing }(S)=\left(M^{*} S\right)\end{array}$ & -0.641 & -3.187 & $* * *$ & -619.041 \\
\hline $\begin{array}{l}\text { Antioxidant-free label }(M) \times \text { conformity with } \\
\text { others }(D)=\left(M^{*} D\right)\end{array}$ & 0.417 & 2.073 & ** & 402.682 \\
\hline $\begin{array}{l}\text { Antioxidant-free label }(M) \times \text { low need for cognition } \\
(N)=\left(M^{*} N\right)\end{array}$ & -0.311 & -1.533 & & -300.442 \\
\hline Organic label dummy (Y) & 0.049 & 0.163 & & 47.536 \\
\hline $\begin{array}{l}\text { Organic label }(Y) \times \text { awareness of dangers of food } \\
\text { additives }(T)=\left(Y^{*} T\right)\end{array}$ & 0.251 & 1.288 & & 242.141 \\
\hline Organic label $(\mathrm{Y}) \times$ knowledge of wine $(\mathrm{W})=\left(\mathrm{Y}^{*} \mathrm{~W}\right)$ & -0.479 & -2.347 & ** & -462.577 \\
\hline $\begin{array}{l}\text { Organic label }(Y) \times \text { knowledge of food processing } \\
(S)=\left(Y^{*} S\right)\end{array}$ & 0.060 & 0.310 & & 57.821 \\
\hline Organic label $(Y) \times$ conformity with others $(D)=\left(Y^{*} D\right)$ & -0.020 & -0.103 & & -19.186 \\
\hline Organic label $(\mathrm{Y}) \times$ low need for cognition $(\mathrm{N})=\left(\mathrm{Y}^{*} \mathrm{~N}\right)$ & -0.181 & -0.933 & & -174.414 \\
\hline Product of France label dummy (F) & -1.119 & -3.241 & $* * *$ & -1080.328 \\
\hline $\begin{array}{l}\text { Product of France label }(F) \times \text { awareness of dangers } \\
\text { of food additives }(T)=\left(F^{*} T\right)\end{array}$ & -0.505 & -2.579 & $* * *$ & -487.365 \\
\hline $\begin{array}{l}\text { Product of France label }(F) \times \text { knowledge of wine } \\
(W)=\left(F^{*} W\right)\end{array}$ & 0.768 & 3.773 & $* * *$ & 742.061 \\
\hline $\begin{array}{l}\text { Product of France label }(F) \times \text { knowledge of food } \\
\text { processing }(S)=(F \times S)\end{array}$ & 0.267 & 1.363 & & 258.135 \\
\hline $\begin{array}{l}\text { Product of France label }(F) \times \text { conformity with others } \\
(D)=\left(F^{*} D\right)\end{array}$ & 0.450 & 2.296 & ** & 434.310 \\
\hline $\begin{array}{l}\text { Product of France label }(F) \times \text { low need for cognition } \\
(N)=\left(F^{*} N\right)\end{array}$ & 0.065 & 0.332 & & 62.956 \\
\hline Product of Chile label dummy (C) & -0.626 & -2.311 & $* *$ & -604.828 \\
\hline $\begin{array}{l}\text { Product of Chile label }(C) \times \text { awareness of dangers } \\
\text { of food additives }(T)=\left(C^{*} T\right)\end{array}$ & -0.516 & -2.563 & ** & -497.957 \\
\hline $\begin{array}{l}\text { Product of Chile label }(C) \times \text { knowledge of wine } \\
(W)=\left(C^{*} W\right)\end{array}$ & 0.563 & 2.791 & *** & 543.592 \\
\hline $\begin{array}{l}\text { Product of Chile label }(C) \times \text { knowledge of food } \\
\text { processing }(S)=\left(C^{*} S\right)\end{array}$ & -0.023 & -0.111 & & -21.861 \\
\hline $\begin{array}{l}\text { Product of Chile label }(C) \times \text { conformity with } \\
\text { others }(D)=\left(C^{*} D\right)\end{array}$ & -0.684 & -3.359 & *** & -660.198 \\
\hline $\begin{array}{l}\text { Product of Chile label }(C) \times \text { low need for } \\
\text { cognition }(N)=\left(C^{*} N\right)\end{array}$ & 0.294 & 1.456 & & 284.047 \\
\hline Female dummy $(J) \times$ antioxidant-free label $(M)=\left(J^{*} M\right)$ & 0.630 & 3.212 & $* * *$ & 608.835 \\
\hline Female dummy $(J) \times$ product of France label $(F)=\left(J^{*} F\right)$ & -0.324 & -1.726 & * & -312.894 \\
\hline Age $(A) \times$ antioxidant-free label $(M)=\left(A^{*} M\right)$ & 0.016 & 0.202 & & 15.763 \\
\hline Age $(A) \times$ organic label $(Y)=\left(A^{*} Y\right)$ & 0.129 & 1.773 & * & 124.984 \\
\hline Age $(A) \times$ product of France label $(F)=\left(A^{*} F\right)$ & -0.098 & -1.266 & & -94.689 \\
\hline Annual income $(I) \times$ antioxidant-free label $(M)=\left(I^{*} M\right)$ & -0.040 & -1.254 & & -39.063 \\
\hline Annual income $(I) \times$ product of France label $(F)=\left(I^{*} F\right)$ & 0.063 & 2.055 & ** & 60.811 \\
\hline Price $(P)$ & -0.001 & -13.991 & $* * *$ & \\
\hline
\end{tabular}


Table 6 Conditional logit model results (Continued)

\begin{tabular}{ll}
\hline Number of samples & 2232 \\
Log likelihood & -1257.492 \\
McFadden's $R$ square & 0.155 \\
\hline Note: ${ }^{*} p<0.1 ; * * 0.05 ;{ }^{* * *} p<0.01$ &
\end{tabular}

Note: ${ }^{*} p<0.1 ;{ }^{* *} p<0.05 ;{ }^{* * *} p<0.01$

label has a substantial impact on consumers' appraisal of wine quality. In particular, we found a large gap in appraised price between consumers aware of the dangers of food additives and consumers knowledgeable about wine or food processing. One reason for this result may be that consumers aware of the dangers of food additives perceive substantial added value in wine that does not contain antioxidant additives, which are food additives. On the other hand, consumers knowledgeable about wine and food processing could possibly hold a strong negative view of antioxidant-free-labeled wine because of their belief that wines made without antioxidant additives are of lesser quality than wines made using traditional methods, which involve the addition of antioxidants. The difference in appraised price between consumers aware of the dangers of food additives and consumers who tend to conform to others may result from the difference in the importance they place on such information, which reflects whether the consumer actively seeks such information or not. These results are similar to previous studies' finding that for food technology, consumers tend to accept the negative information more than the positive information, even if the technology has many merits (Aoki et al. 2010). Moreover, consumers with non-scientific information selected the negative information more (Hayes et al. 2002).

We find that wine with the "organic" label has a lower consumer preference than that with the "antioxidant additive-free" label. For the "organic" label, only the $\mathrm{Y}^{*} \mathrm{~W}$ interaction term was negative and significant, with an appraised price of JPY-463, indicating that when consumers knowledgeable about wine compare wines of the same price from the same source, they judge wines lacking the "organic" label to be of higher quality. It would seem more natural to interpret this as an unwillingness to pay extra for the costs associated with "organic" wine production rather than the result of a negative view of the "organic" concept.

The shipment ratio of domestic wine and imported wine in 2010 was $85,731 \mathrm{kl}$ and $181,173 \mathrm{kl}$, respectively. Since $67.9 \%$ of wine is from foreign countries, it is familiar for Japanese consumer. French wines were the highest selling in 2012 (33.9\%), followed by Chilean wine (21.1\%) (FUI KEIZAI TOKYO 2015). For the "product of France" label, with the exception of the $\mathrm{F}^{*} \mathrm{~T}$ interaction, all interaction terms were positive, with $\mathrm{F}^{*} \mathrm{~W}$ and $\mathrm{F}^{*} \mathrm{D}$ being significant. While consumers aware of the dangers of food additives and consumers with a tendency to conform to others had similar tendencies up to this point, their responses to the "product of France" label diverged. This may be because consumers aware of the dangers of food additives, as a group, exhibit excessive concern for food safety and view foreign products negatively, whereas consumers who tended to conform to others have a particularly favorable impression of wines made in France, which is the most famous wine-producing country in the world. This interpretation is further supported by the fact that consumers who tend to conform to others tended to 
significantly undervalue wines from Chile, which is generally less well known as a wineproducing country. In addition, the $C * T$ and $C * W$ interactions were significantly negative and positive, respectively, indicating that consumers aware of the dangers of food additives tended to prefer domestic (Japanese) wines, while consumers knowledgeable about wine tended to assign a higher value to foreign wines. Comparing the appraised prices of French and Chilean wines, if we consider the overall appraisal of all survey respondents, French wines were below Chilean wines. Given that this result contradicts the pricing observed in the marketplace, it must be interpreted with care.

For the interactions between the female dummy and wine labels, both J*M and $A * Y$ were significant and positive. In other words, compared to men, women have a strong tendency to value the antioxidant-free label. Prior studies report similar findings regarding the safety of beef (Aizaki et al. 2004).

\section{Conclusions}

First, the covariance structural analysis revealed that consumers who are aware of the dangers of food additives and tend to conform to others preferred the antioxidant-free label. With a large number of consumers worried about the safety of food additives, it is apparent that manufacturers are using such labels strategically as a means to reassure consumers. Meanwhile, consumers knowledgeable about wine and food processing disliked additive-free wine, implying that such consumers perceive the addition of antioxidants as necessary to produce high-quality wine. These results suggest a growing demand for wine that knowledgeable consumers consider to be of low quality by consumers in Japan. If, for arguments' sake, we designate additive-free wine as an inferior commodity, we are witnessing adverse selection in Japan's wine market (Gresham's law). In this sense, it is important that the government develop guidelines to regulate such labeling.

Second, the conjoint analysis demonstrated that the appraised value of "additive-free" and other labels varied substantially depending on consumers' individual attributes. In particular, consumers aware of the dangers of food additives and those knowledgeable about wine had opposite responses for all labels. It appears that Japan's wine industry, as a whole, is currently putting effort into developing wines that reflect the needs of general consumers (additive-free, organic, domestic, etc.) and not on developing wines sought by consumers knowledgeable about wine. Furthermore, if this trend continues, the gap in quality between Japanese wine and traditional, foreign wines will only grow wider. For Japanese wine to meet international standards, it is not only necessary for wine producers to make an effort to improve the quality of their product but also essential that consumers increase their awareness so they can properly assess the value of a good wine. As such, promoting and disseminating accurate information about risk will be an important strategy in achieving this end.

Finally, the limitation of our study is that our targeted respondents are those who buy or drink wine. These respondents seem to have relatively good knowledge about wine. Therefore, there is a possibility of overestimation. In addition, the fact that the problem of adverse selection was elucidated even under such circumstances indicates that measures should be implemented as soon as possible in order to reduce consumers' misunderstandings. 


\section{Abbreviations}

CMO: Common market organization; EU: European Union; GM: Genetically modified; JPY: Japanese yen; SEM: Structural equation model; WTA: Willingness to accept; WTP: Willingness to pay

\section{Authors' contributions}

All authors designed the research. HS collected and analyzed the data. SK participated in drafting the manuscript. All authors read and approved the final manuscript.

\section{Competing interests}

The authors declare that they have no competing interests.

\section{Author details}

'Department of Animal and Food Hygiene, Obihiro University of Agriculture and Veterinary Medicine, Nishi 2-11, Inada-cho, Obihiro, Hokkaido 080-8555, Japan. ${ }^{2}$ Tokai Denpun Co., Ltd., Shizuoka 420-0858, Japan.

Received: 4 April 2016 Accepted: 23 February 2017

Published online: 09 March 2017

\section{References}

Aizaki H, Sato K, Kikkawa T, Sawada M (2004) Effects of attitudes concerning food safety on choice behavior of beef: a choice experiment including social-psychological factors (written in Japanese). Jpn J Farm Manage 42(2):22-32

Aoki K, Shen J, Saijo T (2010) Consumer reaction to information on food additives: evidence from an eating experiment and a field survey. J Econ Behav Organ 73(3):433-438. doi:10.1016/j.jebo.2009.11.007

Arahata K (2004) The wine market in Japan: market competition among exporting countries and the strategy of US wine. Selected paper prepared for presentation at the American Agricultural Economics Association Annual Meeting, Colorado, pp 1-26

Bearth A, Cousin ME, Siegrist M (2014) The consumer's perception of artificial food additives: influences on acceptance, risk and benefit perceptions. Food Qual Prefer 38:14-23. doi:10.1016/j.foodqual.2014.05.008

Cacioppo JT, Petty RE, Kao CF (1984) The efficient assessment of need for cognition. J Pers Assess 48(3):306-307. doi:10. 1207/s15327752jpa4803_13

Comité Européen des Entreprises Vins (CEEV) (2016a) About the EU wine sector. Comité Vins, Brussels. http://www.ceev. eu/about-the-eu-wine-sector. Accessed 02 Nov 2016

Comité Européen des Entreprises Vins (CEEV) (2016b) Internal market and food safety. Comité Vins, Brussels. http://ceev. eu/policy-dossiers/internal-market-food-safety. Accessed 02 Nov 2016

Dhar R, Nowlis SM (1999) The effect of time pressure on consumer choice deferral. J Consum Res 25(4):369-384. doi:10. 1086/209545

Finch G (2016) Allergens labelling for wine. Food Standards Agency, London, https://www.food.gov.uk/sites/default/ files/multimedia/pdfs/enforcement/wineallergenlabeloct13.pdf. Accessed 23 Nov 2016

Fuji Keizai Tokyo (2015) 2016 handbook of food marketing no.2 (written in Japanese). Fuji Keizai, Tokyo, pp 274-287

Hansen J, Holm L, Frewer L, Robinson P, Sandoe P (2003) Beyond the knowledge deficit: recent research into lay and expert attitudes to food risks. Appetite 41:111-121. doi:10.1016/S0195-6663(03)00079-5

Hayes DJ, Fox JA, Shogren JF (2002) Experts and activists: how information affects the demand for food irradiation. Food Policy 27(2):185-193. doi:10.1016/50306-9192(02)00011-8

Hox JJ, Bechger TM (1998) An introduction to structural equation modeling. Family Sci Rev 11(4):354-373

Ikumoto T, Maruyama T, Murakami K, Hayashi K (2011) Consumers' belief and disclosure: a conjoint analysis of the vegetable oil market (written in Japanese). Stud Appl Econ 5:164-175

Japan's National Tax Agency (2008) Questionnaire survey about wine (written in Japanese). Japan's National Tax Agency, Tokyo, http://www.nta.go.jp/tokyo/shiraberu/sake/topic/ques/topic-total03.htm. Accessed 24 Mar 2016

Japan's National Tax Agency (2015) Outline of manufacturing industry for fruit liquor (Research on FY2014) (written in Japanese). Japan's National Tax Agency, Tokyo, https://www.nta.go.jp/shiraberu/senmonjoho/sake/shiori-gaikyo/ seizogaikyo/kajitsu/pdf/h26.pdf. Accessed 02 Nov 2016

Kaplan DW (2008) Structural equation modeling: foundations and extensions. SAGE Publications Inc, Thousand Oaks

Li Q, McCluskey JJ, Wahl TI (2004) Effects of information on consumers' willingness to pay for GM-corn-fed beef. J Agric Food Ind Organ 2(2):1-18. doi:10.2202/1542-0485.1058

Lusk JL, Roosen J, Fox JA (2003) Demand for beef from cattle administered growth hormones or fed genetically modified corn: a comparison of consumers in France, Germany, the United Kingdom, and the United States. Am J Agric Econ 85(1):16-29. doi:10.1111/1467-8276.00100

Markosyan A, McCluskey JJ, Wahl TI (2009) Consumer response to information about a functional food product: apples enriched with antioxidants. Can J Agric Econ 57(3):325-341. doi:10.1111/j.1744-7976.2009.01154.x

McCluskey JJ, Grimsrud KM, Ouchi H, Wahl TI (2003) Consumer response to genetically modified food products in Japan. Agric Resour Econ Rev 32(2):222-231

Ough CS, Crowell EA (1987) Use of sulfur dioxide in winemaking. Food Sci 52(2):386-388. doi:10.1111/j.1365-2621.1987. tb06620.x

Statistics Bureau, Ministry of Internal Affairs and Communications (2011) National population census (Research on FY2010) (written in Japanese). Statistics Bureau, Ministry of Internal Affairs and Communications, Tokyo, http://www. stat.go.jp/data/kokusei/2010/. Accessed 22 Feb 2017

Statistics Bureau, Ministry of Internal Affairs and Communications (2013) Employment status survey (Research on FY2012) (written in Japanese). Statistics Bureau, Ministry of Internal Affairs and Communications, Tokyo, http://www. stat.go.jp/data/shugyou/2012/index2.htm\#kekka. Accessed 22 Feb 2017

Verplanken B (1993) Need for cognition and external information search: responses to time pressure during decisionmaking. J Res Pers 27(3):238-252. doi:10.1006/jrpe.1993.1017 